\title{
Optimization Method for Girder of Wind Turbine Blade
}

\author{
Yuqiao Zheng, ${ }^{1}$ Rongzhen Zhao, ${ }^{2}$ and Hong Liu ${ }^{1}$ \\ ${ }^{1}$ Key Laboratory of Digital Manufacturing Technology and Application, The Ministry of Education, \\ Lanzhou University of Technology, Lanzhou 730050, China \\ ${ }^{2}$ School of Mechanical and Electronical Engineering, Lanzhou University of Technology, Lanzhou 730050, China
}

Correspondence should be addressed to Rongzhen Zhao; zhaorongzhen@lut.cn

Received 19 February 2014; Accepted 22 April 2014; Published 24 July 2014

Academic Editor: Weichao Sun

Copyright (C) 2014 Yuqiao Zheng et al. This is an open access article distributed under the Creative Commons Attribution License, which permits unrestricted use, distribution, and reproduction in any medium, provided the original work is properly cited.

This paper presents a recently developed numerical multidisciplinary optimization method for design of wind turbine blade. The objective was the highest possible blade weight under specified atmospheric conditions, determined by the design giving girder layer and location parameter. Wind turbine blade on box-section beams girder is calculated by ply thickness, main girder and trailing edge. In this study, a realistic $30 \mathrm{~m}$ blade from a 1.2 MW wind turbine model of blade girder parameters is established. The optimization evolves a structure which transforms along the length of the blade, changing from a design with spar caps at the maximum thickness and a trailing edge mass to a design with spar caps toward the tip. In addition, the cross-section structural properties and the modal characteristics of a $62 \mathrm{~m}$ rotor blade were predicted by the developed beam finite element. In summary, these findings indicate that the conventional structural layout of a wind turbine blade is suboptimal under the static load conditions, suggesting an opportunity to reduce blade weight and cost.

\section{Introduction}

As wind turbines continue to grow in size, it becomes increasingly important to ensure that they are as structurally efficient as possible to ensure that wind energy can be a cost-effective source of power generation. Aerodynamic and structural optimization has become a subject of considerable interest. It involves the determination of the geometry of an aerodynamic configuration that satisfies certain objectives subject to constraints $[1,2]$. Blade is one of the critical components of wind driven generator. Now, domestic and foreign large wind turbine blades are made of composite material layer. For the design and optimization of wind turbine blades, knowledge about the state of the boundary layers at the rotor is important since the energy yield strongly depends on this issue. Blades with an extended laminar boundary layer zone offer a higher energy yield. The use of composite materials makes blade design more flexible, but the design of the blades and the analysis put forward higher request. The ultimate goal is a direct design process, where the design space is searched for the optimum design in an automatic and systematic way $[3,4]$.
The shape of wind turbine blades is complicated. The main bearing structure of blade is the main girder of the blade; the structure design of the main girder is a key part of the blade design. Composite material structure design generally uses allowable strain design.

The structural design of the blade mainly includes two aspects; one is the section of the blade structure; the other is section layer material selection and arrangement and calculating the thickness of layers. The main girder structure of large wind turbine blades is mainly double shear web girder or box girder at present [5]. With the increasing of wind turbine blade size, the using of double shear web girder and box girder structure can satisfy the requirement of the stiffness and strength of the blade and reduce greatly quality of the blades; the passage which takes box girder as the object is studied [6]. Blade section structure of box girder relates mainly to the determination of the location and width of the girders, and the determination of main parameters of the main girder affects calculation of the layer thickness. As a case study the model is applied to the design of a $1.2 \mathrm{Mw}$ wind turbine blade. The model has been found to be successful 


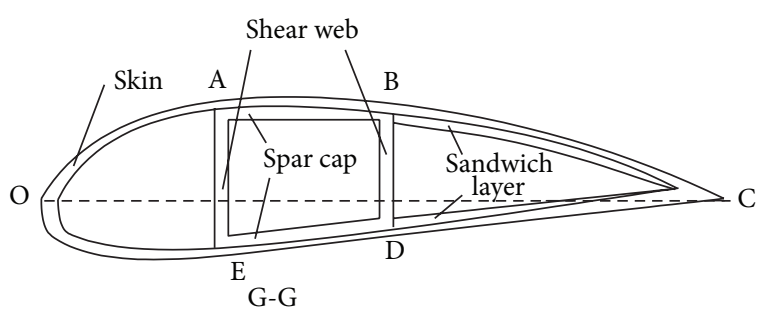

FIgURE 1: Cross-section of blade.

in arriving at optimum blade designs and identifying useful design trends with various design specifications.

\section{Approach and Methods}

The considered blade is made of composite materials containing more than one bonded material, each with different structural properties.

Figure 1 is the schematic diagram of the blade profile structure; the layer thickness can be calculated according to the given profile structure. The layer thickness of front AOE contains only bidirectional cloth layer thickness; that is, $t_{\mathrm{LE}}=t_{\mathrm{db}}$. The layer thickness of girder cap AB, ED includes bidirectional and unidirectional cloth thickness; that is, $t_{\mathrm{SC}}=$ $t_{\mathrm{db}}+t_{\mathrm{ud}}$. The layer thickness of the trailing edge BCD comprises a bidirectional cloth and sandwich layup; that is, $t_{\mathrm{TE}}=$ $t_{\mathrm{db}}+t_{o}$. The layer thickness of shear web AE, BD can generally be assumed to be the same as the trailing edge; that is, $t_{\mathrm{SW}}=t_{\mathrm{TE}}=t_{\mathrm{db}}+t_{o}$.

The skin and the shear web thickness should be given before the thickness of the main girder of blade; skin is mainly laid bidirectional cloth and bidirectional cloth is mainly used to bear the torque, but actually the torque is borne by blade, small thickness given in [7]. Consider

$$
t_{\mathrm{db}}=\max \left(0.0025 \cdot \max \left(w_{p i}\right), m_{\mathrm{db}} \cdot \delta_{\mathrm{dbp}}\right),
$$

where $w_{p i}$ means width of the panel between the $i$ web and the $i+1$ web; $\delta_{\mathrm{dbp}}$ is bidirectional fabric single-layer thickness; $m_{\mathrm{db}}$ is the least layers of bidirectional fabric single-layer. It assumes that the thickness of entire cross-section of bidirectional cloth layer is consistent when calculated. The main girder ply mainly unidirectional cloth; its thickness can be iterative calculation by strength criterion given in [8]. Consider

$$
\begin{gathered}
f\left(\delta_{\mathrm{ud}}\right)=\sigma_{\max }-[\sigma], \\
\sigma=E\left[\frac{M_{1} y}{E I_{1}}-\frac{M_{2} x}{E I_{2}}+\frac{N}{E A}\right],
\end{gathered}
$$

where $\sigma_{\max }=\max (\sigma)$. Consider

$$
N_{\mathrm{cr}}=4 \cdot \frac{\pi^{2} D}{b^{2}} .
$$

From the above equations, $(x, y)$ represents the discrete point coordinates on the girder, $\sigma$ represents the stress of the specified point in the blade section, $M_{1}, M_{2}$ represent

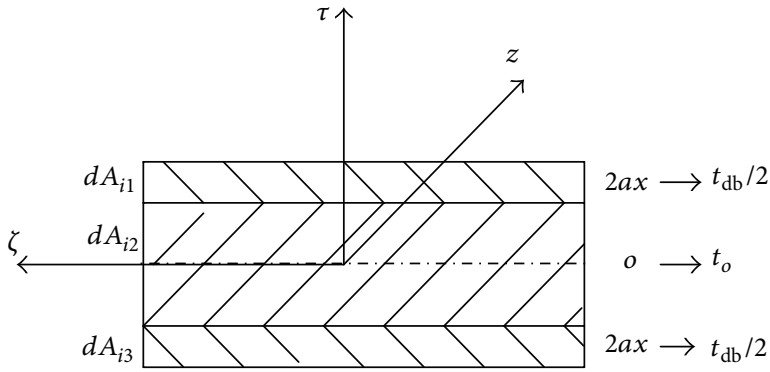

FIgURE 2: Schematic diagram of area element at trailing edge.

bending that is suffered, respectively, from the first and second axis direction, $N$ is the normal force, $E A$ is longitudinal stiffness of the blade, and $E I_{1}, E I_{2}$, and $E$ are the first and the second main shaft bending stiffness and elastic modulus at this point, respectively.

Front curvature is larger and main girder bending ability is stronger, so it assumes that front and main girder buckling instability does not occur. The airfoil trailing edge of the blade section is generally wider and its curvature is small; it is easy to have an instability problem. In order to enhance its stiffness, it lays this sandwich layer; generally the trailing edge of the blade profile is assumed as plate to calculate the antibuckling thickness. The trailing edge is simplified as flat as shown in Figure 2. thickness direction the plate of $z-\zeta$ is neutral level, in the direction of $\tau$ is the plate thickness direction.

Corresponding to calculation formula (7), the critical buckling stress is simplified.

Where $N_{\text {cr }}$ is critical load, $D$ is bending stiffness of plate and $b$ is the width of the plate. It should be noticed that the isotropic material and trailing edge portion of laminates were calculated bidirectional cloth and sandwich layup bending stiffness and it is defined by the following forms:

$$
\begin{aligned}
D_{\mathrm{db} 1}=D_{\mathrm{db} 2} & =\int_{\delta_{o} / 2}^{\left(\delta_{o}+\delta_{\mathrm{db}}\right) / 2} \frac{E_{\mathrm{db}}}{1-v_{\mathrm{db}}^{2}} \tau^{2} \mathrm{~d} \tau \\
& =\frac{E_{\mathrm{db}}}{1-v_{\mathrm{db}}^{2}}\left(\frac{1}{24} t_{\mathrm{db}}^{3}+\frac{1}{8} t_{\mathrm{db}}^{2} t_{o}+\frac{1}{8} t_{\mathrm{db}} t_{o}^{2}\right), \\
D_{o} & =\int_{-\delta_{o} / 2}^{\delta_{o} / 2} \frac{E_{o}}{1-v_{o}^{2}} \tau^{2} \mathrm{~d} \tau=\frac{E_{o}}{1-v_{o}^{2}}\left(\frac{1}{12} t_{o}^{3}\right),
\end{aligned}
$$

where $E_{\mathrm{db}}, v_{\mathrm{db}}$ are, respectively, bidirectional fabric elastic modulus and Poisson's ratio. The longitudinal stress of plate can be written as follows:

$$
N_{z}(z, \zeta)=\int_{\tau_{1}}^{\tau_{2}} \sigma(z, \zeta, \tau) \mathrm{d} \tau
$$

where $\sigma(z, \zeta, \tau)$ is the axial bending stress and $N_{z}(z, \zeta)$ is the longitudinal pressure of unit length. 
Substituting (4) and (5)) into (3), it can be expressed as follows:

$$
\begin{aligned}
\frac{N_{z}(z, \zeta) \cdot b^{2}}{4 \pi^{2}}= & \left(\frac{1}{12} \frac{E_{o}}{1-v_{o}^{2}}\right) \cdot \delta_{o}^{3}+\left(\frac{1}{4} \frac{E_{\mathrm{db}}}{1-v_{\mathrm{db}}^{2}} \cdot \delta_{\mathrm{db}}\right) \cdot \delta_{o}^{2} \\
& +\left(\frac{1}{4} \frac{E_{\mathrm{db}}}{1-v_{\mathrm{db}}^{2}} \cdot \delta_{\mathrm{db}}^{2}\right) \cdot \delta_{o}+\frac{1}{12} \frac{E_{\mathrm{db}}}{1-v_{\mathrm{db}}^{2}} \delta_{\mathrm{db}}^{3} .
\end{aligned}
$$

\section{Optimization Problem Definition}

It is not possible to formulate the problem of optimum design of wind turbine blades as a single-criterion optimisation task because this process requires many criteria to be taken into account. Blade design is here performed with a constrained optimization-based procedure. In formulating an optimization problem, three principal phases must be considered $[9,10]$ :

(i) definition and measure of design objectives,

(ii) choice of the design variables and preassigned parameters,

(iii) definition of the design constraints.

The blade profile structure is shown in Figure 1, given girder location and width parameters, and it defines the ratio which distance that from shear web of before the main girder to front end divides section length is $a$, section width of main girder and section chord ratio is $b$.

3.1. Form of the Objective Function. The objective function is linear density of blade mass. Based on the study of [7], it can be expressed as follows:

$$
\widetilde{G}=\min \left(\sum_{i=0.2 R}^{R} G_{i}\right)
$$

In order to decrease dimensionality of the optimization problem, some of the variables are preassigned fixed values. They are (a) layout parameters including blade length, chord, twist, and precone and (b) cross-sectional parameters including airfoil type and dimensions of internal webs and covering skin. The design variables, which are subject to change in the optimization process, are chosen to be the dimensionless radius of gyration, cross-sectional area, and length of each segment composing the main blade spar [11].

For thin-walled sections with constant, if the profile is discrete, blade sectional area of the first $i$ can be expressed as follows:

$$
A_{i}=l_{\mathrm{db}} \delta_{\mathrm{db}}+l_{\mathrm{ud}} \delta_{\mathrm{ud}}+l_{o} \delta_{o}
$$

where $l_{\mathrm{db}}, l_{\mathrm{ud}}$, and $l_{o}$ are, respectively, bidirectional fabric, unidirectional fabric, and sandwich layer laminate length; $\delta_{\mathrm{db}}, \delta_{\mathrm{ud}}$, and $\delta_{o}$ are, respectively, bidirectional cloth, unidirectional cloth, and sandwich layer thickness. Taking the main girder cap layup as an example, which is calculated from the following equation:

$$
l_{\mathrm{AB}}=\sum_{i=1}^{n-1} \sqrt{\left(x_{i+1}-x_{i}\right)^{2}+\left(y_{i+1}-y_{i}\right)^{2}} \text {, }
$$

where $\left(x_{i}, y_{i}\right)$ is coordinates of the point on the main girder cap $\mathrm{AB}$, the values range of $\left(x_{i}, y_{i}\right)$ is determined by $a, b$. So the section quality of the first $i$ of blade can be represented as follows:

$$
G_{i}=l_{\mathrm{db}} \delta_{\mathrm{db}} \rho_{\mathrm{db}}+l_{\mathrm{ud}} \delta_{\mathrm{ud}} \rho_{\mathrm{ud}}+l_{o} \delta_{o} \rho_{o}
$$

Finally, it can be expressed as follows:

$$
G_{i}=f(a, b)
$$

3.2. The Constraints. After having carried out the study of formulating an optimisation criterion when minimising quality, all design requirements are treated as constraints; therefore, all converged solutions are viable according to the conditions that have been imposed by the designer. The code performs the design using a multilevel approach. Considering blades as double shear webs, it will be meaningless if the distance from anterior shear web to front end, the initial position of main girder along cross-section chord of blade which is the location $a$ of former shear web, the girder width parameters of $a$ and $b$ should be less than 1 , if it is more than 1 , it indicates that the main girder is clearly beyond the scope of the section:

$$
\begin{gathered}
\operatorname{Min}(\widetilde{G})=F(a, b) \\
\text { s.t }: 0 \leq a+b \leq 1, \quad \max \left(E I_{1}\right) \geq C .
\end{gathered}
$$

From the above equations, $\widetilde{G}$ indicates the quality of the blade section, variables are the former web location parameters $a$ and girder width parameter $b$, and $\max \left(E I_{1}\right)$ is the maximum of the first main shaft bending stiffness in all calculation sections of blade profile. $C$ is the maximum of the first main shaft bending stiffness in blade calculation section before optimization of the blade, where

$$
0.1 \leq a \leq 0.89 \quad 0.1 \leq b \leq 0.9, \quad 0 \leq a+b \leq 1 .
$$

The values of $a$ and $b$ gained optimization will be randomly eliminated when these are inappropriate variable values. If only the quality of blade is required to be the minimum, it will lead to the decrease of blade stiffness. Therefore, it needs to make the blade stiffness constraints in the optimization process. Blade bending stiffness considers mainly the stiffness of blade-wielding direction, and that is the first main shaft bending stiffness of blade profile corresponding to the calculation; the constraints given are $\max \left(E I_{1}\right) \geq C$ in this formula, where $C$ is the constant. 


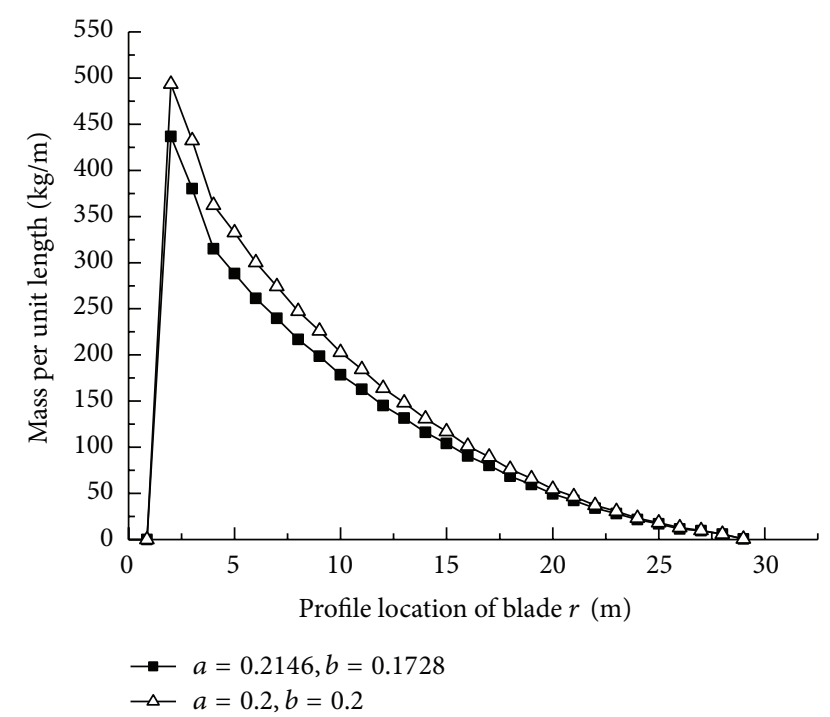

FIGURE 3: Mass per unit length comparison after optimization.

TABLE 1: Parameters comparison after optimization.

\begin{tabular}{lcc}
\hline Parameters & Before optimization & After optimization \\
\hline$a$ & 0.2 & 0.2146 \\
$b$ & 0.2 & 0.1728 \\
$E I_{1} / \mathrm{N} \cdot \mathrm{m}^{2}$ & $2.35 E+0.8$ & $2.77 E+08$ \\
$E I_{2 \max } / \mathrm{N} \cdot \mathrm{m}^{2}$ & $1.84 E+08$ & $1.71 E+08$ \\
\hline
\end{tabular}

\section{Optimization of a 1.2 MW Wind Blade}

4.1. The Determination of Basic Parameters. In this study, a megawatt wind turbine blade will be computed layer and the placement parameters of the main girder will be optimized by genetic algorithm. When it is programmed with genetic algorithm, MATLAB genetic algorithm toolbox which is made up by Sheffield University swill be used. Genetic algorithm parameters are as follows: the population size is 280 , the maximum algebra of evolution is 470 , variable dimension is 2 , and crossover rate is 0.35 .

4.2. The Results of Calculation and Analysis. Optimisation calculations were done with the use of the thors program that implemented a modified genetic algorithm for which the following assumptions were made. The specific results are shown in Table 1 and Figures 3, 4, 5, and 6 for the optimization design of box girder position and width parameters.

It is not convenient to consider the blade root when it is calculated, so it must be designed separately. Table 1 shows the difference of the main girder parameters before and after optimization. Before the shear web position shifts slightly backward and girder width also increases after optimization in the case that bending stiffness does not reduce. Figure 2 shows the comparison of quality linear density of different spanwise positions before and after optimization; in general, the summation of quality linear density has decreased but it is not so much; it is reduced relatively more in the blade

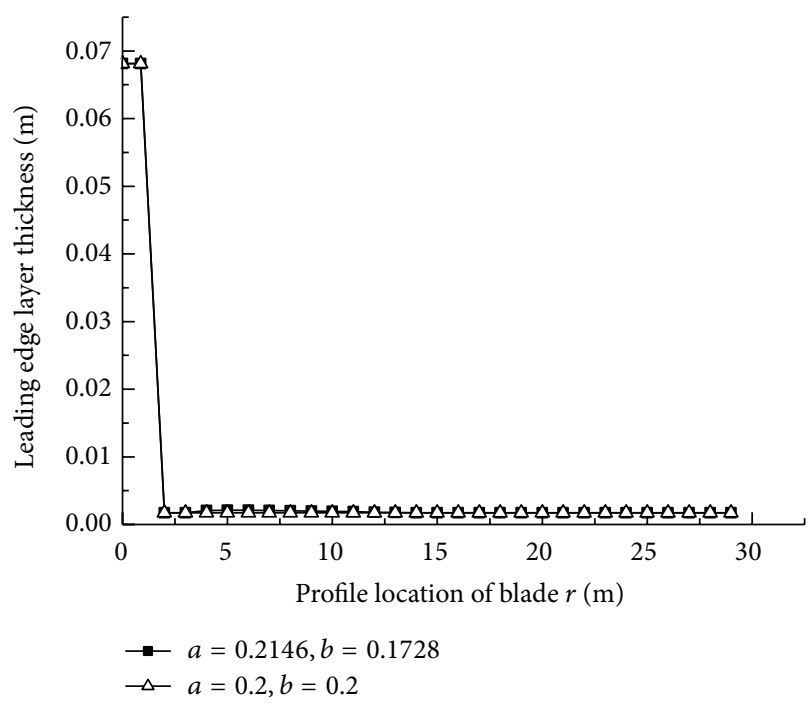

FIgURE 4: Leading edge layer thickness.

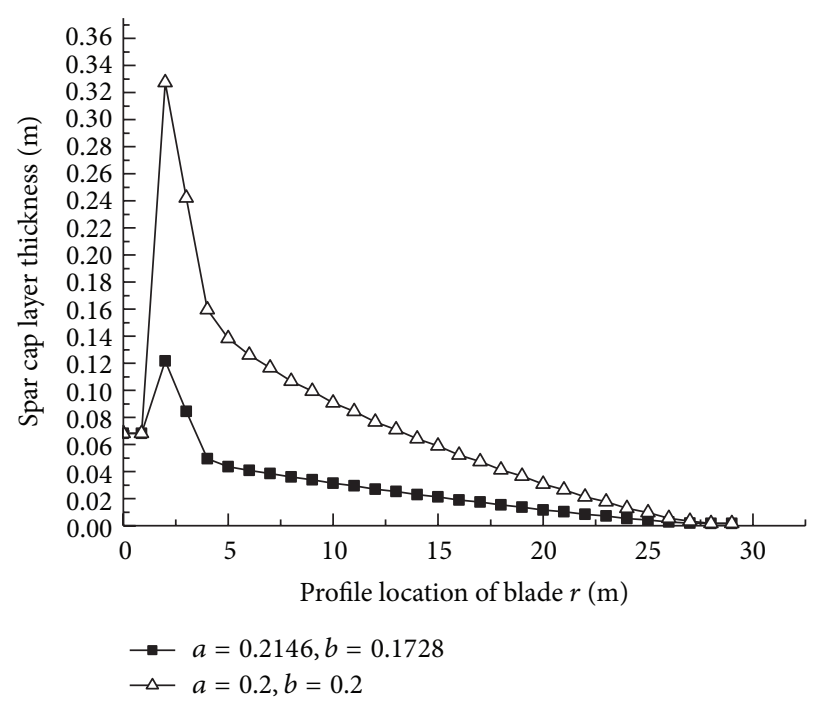

FIGURE 5: Spar cap layer thickness.

length $10 \%$. It is mainly affected by the stiffness constraint, so the reduction of quality of blade is not very obvious after optimization.

As illustrated in Figure 4 in the comparison of the front layer thickness before and after optimization, the front layer is almost not changed, because the front is only lain a bidirectional cloth, the estimation of bidirectional fabric thickness is associated with the distance between front and rear shear webs, and the bidirectional fabric thickness is almost not changed after optimization because the change of girder width is not so obvious.

As can be seen in Figure 5, the use of large fiber angles in the spar caps should be avoided to limit the impact on the blade mass. Comparing with the main girder cap layer thickness, the middle part of the main girder cap layer thickness decreases obviously; although the percentage of girder width increase is small, the middle chord length of blade 


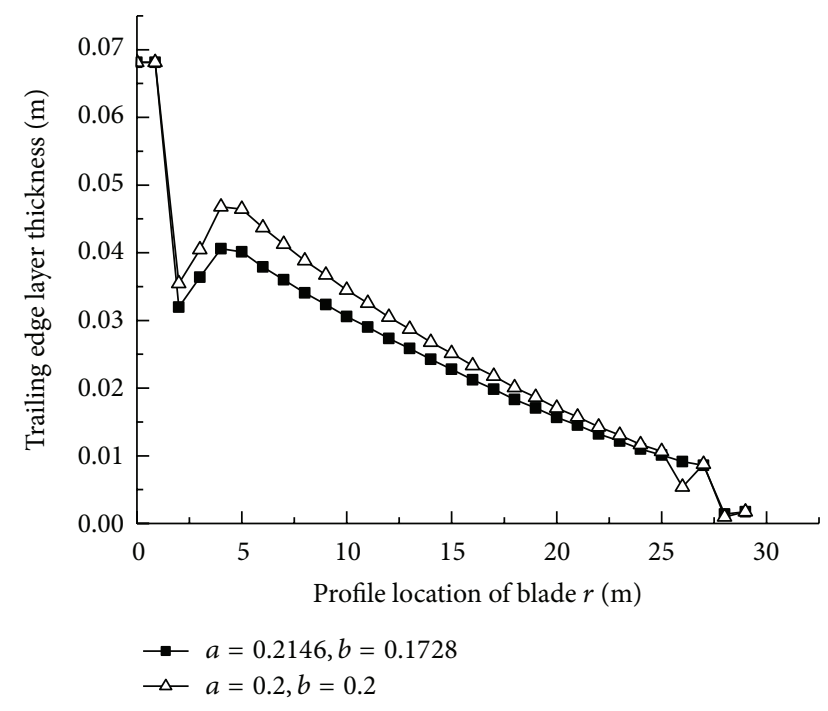

FIgURE 6: Trailing edge layer thickness.

is bigger, so overall the incremental volume of the main girder width is obvious; this part of the corresponding layer thickness is also reduced obviously.

Figure 6 is comparison of the trailing edge thickness; it can be seen from Figure 6 that the ply thickness which is close to the maximum chord is reduced obviously, because the increase of girder width reduces the trailing edge width and at the same time reduces the sandwich layer laying quantity.

The layer depth value of girder section near the blade root is very large, which causes error according to the committee airfoil calculation given; the actual blade in the transition section profile by is changed airfoils to round shape.

\section{Conclusion}

We presented our latest developments toward a direct design method for HAWTs. The design method was based on numerical optimization and several calculation models: aerodynamic calculations and structural calculations. An optimization model is developed by constraining blade stiffness, taking minimum quality of blade as the objective function, and calculating the parameters of main girder of blade with genetic algorithm. By optimizing calculations, the position of the main girder of blade shifts toward the rear edge and its width increases somewhat. The synergistic use of fiber rotations in the skin and spar caps is beneficial in terms of blade weight. In fact, fiber rotations in the skin allow one to limit rotations in the spar caps. The multidisciplinary optimization model is found to be appropriate and efficient in arriving at optimum blade designs and identifying useful design trends with various design specifications.

\section{Conflict of Interests}

The authors declare that there is no conflict of interests regarding the publication of this paper.

\section{Acknowledgments}

The authors would like to acknowledge the financial support made available through the Natural Science Foundation (no. 51165019), the Natural Science Foundation of GANSU Province (no. 1308RJYA018), and the Fundamental Research Funds for the Lanzhou city technology bureau projects (no. 2013-4-110). These supports are gratefully acknowledged.

\section{References}

[1] M. R. Islam, S. Mekhilef, and R. Saidur, "Progress and recent trends of wind energy technology," Renewable and Sustainable Energy Reviews, vol. 21, no. 1, pp. 456-288, 2013.

[2] A. W. Dahmouni, M. Ben Salah, F. Askri, C. Kerkeni, and S. Ben Nasrallah, "Assessment of wind energy potential and optimal electricity generation in Borj-Cedria, Tunisia," Renewable and Sustainable Energy Reviews, vol. 15, no. 1, pp. 815-820, 2011.

[3] Guidelines for Design of Wind Turbines, Det NorskeVeritas and Riso National Laboratory, Jydsk Centraltrykkeri, Denmark, 2nd edition, 2002.

[4] Q. Shi and C. Chen, "Compute of geometric parameters of any thin sections," Chinese Journal of Mechanical Engineering, vol. 40, no. 10, pp. 144-148, 2004.

[5] C.-C. Liao, J.-L. Wang, K.-Z. Shi, and J.-Z. Xu, "Optimization design on wind turbine blade sectional stiffness," Journal of Engineering Thermophysics, vol. 31, no. 7, pp. 1127-1130, 2010.

[6] M. Zhiyong, Large Wind Power Blade Structure Design Method Research, north China Electric Power University, Beijing, China, 2011.

[7] E. A. Bossanyi, "Individual blade pitch control for load reduction," Wind Energy, vol. 6, no. 2, pp. 119-128, 2003.

[8] K. Y. Maalawi and H. M. Negm, "Optimal frequency design of wind turbine blades," Journal of Wind Engineering and Industrial Aerodynamics, vol. 90, no. 8, pp. 961-986, 2002.

[9] L.-C. Forcier and S. Joncas, "Development of a structural optimization strategy for the design of next generation large thermoplastic wind turbine blades," Structural and Multidisciplinary Optimization, vol. 45, pp. 889-906, 2012.

[10] M. Wang, MATLAB 6.0 and Scientific Computing, Electronic Industry Press, Beijing, China, 2002.

[11] T.-H. Cheng and I.-K. Oh, "Fluid-structure coupled analyses of composite wind turbine blades," Advanced Materials Research, vol. 26-28, pp. 41-44, 2007. 


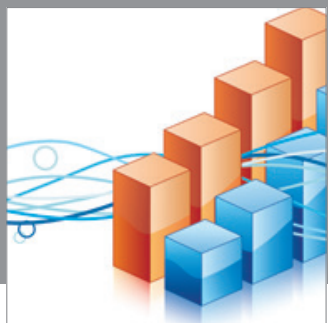

Advances in

Operations Research

mansans

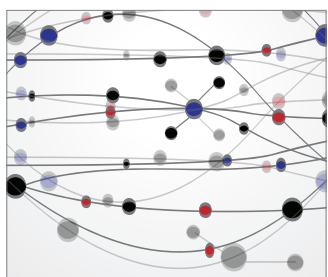

The Scientific World Journal
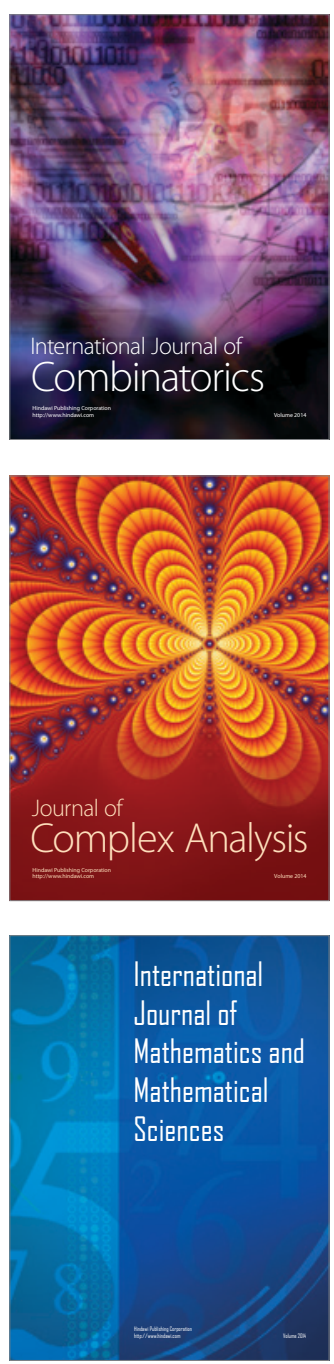
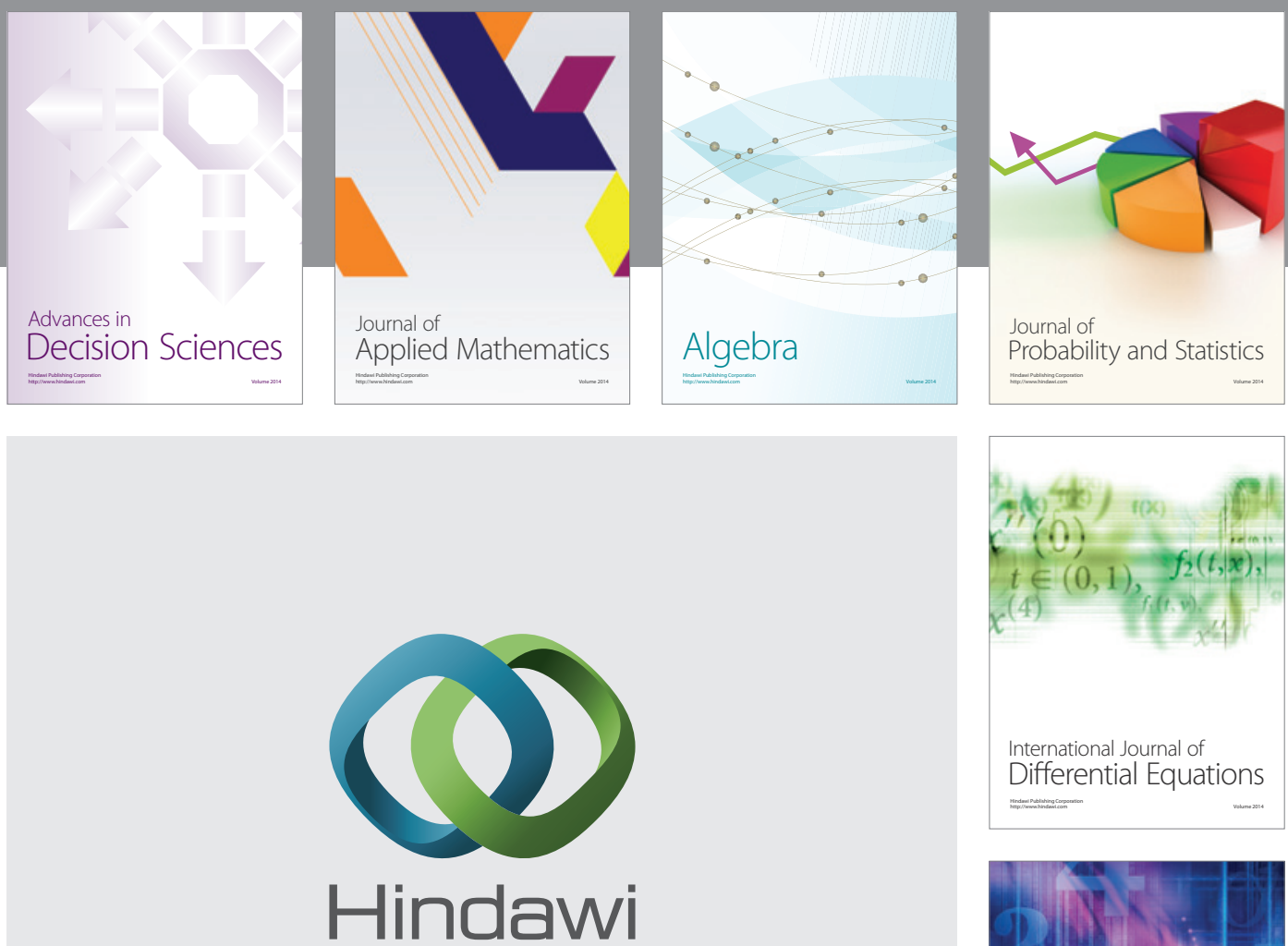

Submit your manuscripts at http://www.hindawi.com
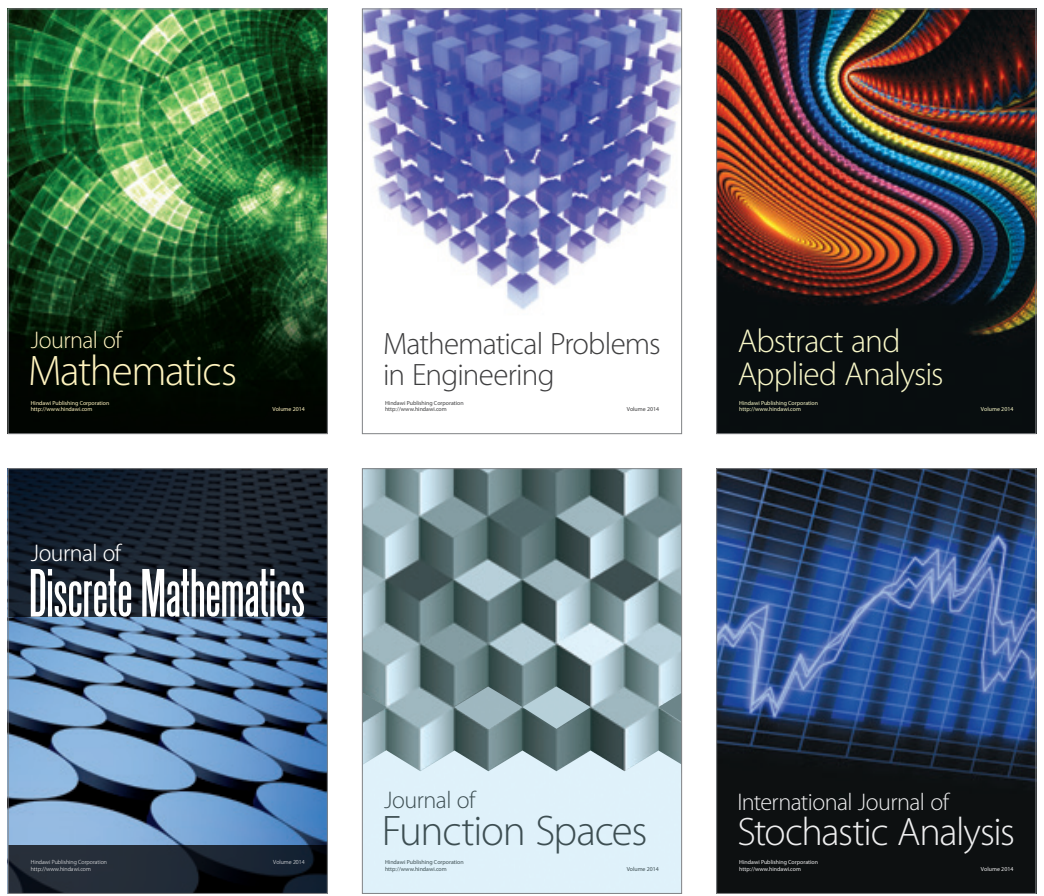

Journal of

Function Spaces

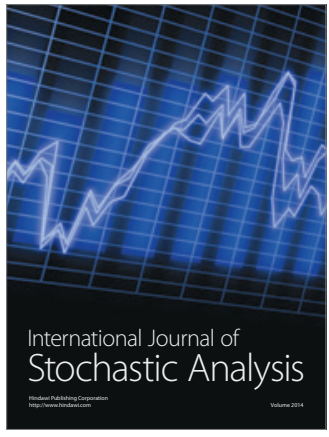

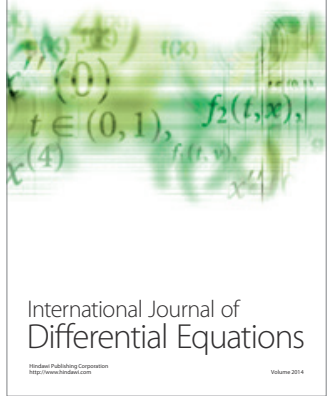
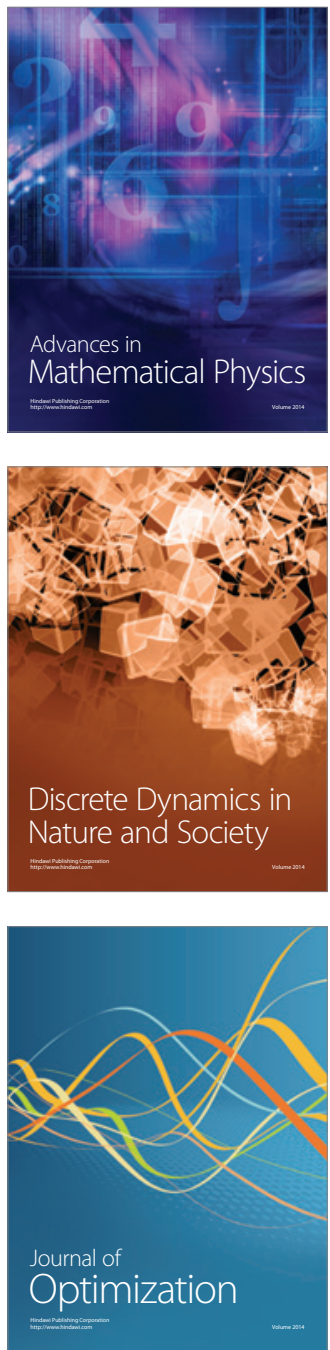